\title{
Workshop Summary and Closing Remarks
}

\author{
by
}

\author{
K.A. Armson, R.P.F. ${ }^{1}$
}

\section{Introduction}

First, I wish to go back to what we were given to expect from this workshop by Ron Christie in his keynote address. $\mathrm{He}$ said the objective was to try to answer the questions, "Can we do it better?" and "How?", that meant we had to have a sense of what is "better". He emphasized something we all know but which is always worth repeating and was also very clearly put by Monte Hummel. Ontarians have to be satisfied that their forests are being managed in their interests and how they want them managed. At stake is our collective credibility. Christie admonished us to clearly define our objectives, do the best we can to achieve those objectives, and communicate clearly.

For me there were three basic packages or components that emerged in our diccussion: Structure, Development, Investment. I'll try tying them up for you, hopefully in a coherent way.

\section{Structure}

There were two types of structure, biological and institutional. The biological ones are those we are trained professionally to deal with and I am including both the organisms and the forests they inhabit in the term structure. What seemed important was not the fact that there was more knowledge to be gained - that will always be the case, but rather that the temporal and spatial aspects of these structures are so important and are not being fully taken into account. In the case studies, stand age and the interval between harvesting emerged as key factors. Does it make sense to block-cut a 120-year-old stand and not return for 15 or so years? Trees and stands occupy fixed space and while their structure changes over time measured in decades, the moose population is relatively mobile on a daily or weekly basis. The definition of the area being managed as distinct from that where the harvest is taking place is just as critical for moose as for trees.

Structures in terms of population and forest stand dynamics thus become critical in allocating and scheduling forest management activities. Further, management can only be planned when the objectives are clearly defined at the outset and capable of being monitored over time.

Institutional structures, about which our collective knowledge gap is surely minimal, are where we appear to

Provincial Forester, Ontario Ministry of Natural Resources. have considerable difficulty. A message that came through clearly was that the constraints of institutional structures can be minimized if there is full communication and honest discussion up front.

\section{Development}

We are taking initial steps in our operational scale management as the case studies illustrated. I've already suggested that we had better pay greater attention to structural attributes especially as related to time and space in planning our scheduling and allocation. What else have we learnt? Two features stand out.

First, it is dangerous and professionally irresponsible to draw firm conclusions from operational trials one or two years after treatment. Foresters did a lot of this in the early 1960's when we were developing our regeneration practices and learned that premature conclusions can be a hazard to future developments.

Second, the case studies presented in this workshop are experiential not experimental. Beware of pseudo-science. We have to learn from using our available knowledge, together with clearly defined objectives and planning and implementation activities. Following this we must monitor and assess in a measurable way what has been achieved. This is the essence of adaptive management. From it will arise specific problem definition which will stimulate research. Research that can answer mangement's needs, for the most part, can only flow after the management activities have been tried, not before.

In mentioning adaptive management I cannot resist two Baskerville quotes - "trivial goals give rise to trivial management" and "act local and think global". I consider these points germane to our discussions.

In development we are dealing with planning, doing and assessing - management in other words. No one can effectively manage if the process is an adversarial one. The simple regulation of resource use arises historically from monarchical rights and punitive actions for those who disobeyed. That mindset is still with many and I would suggest it is a constraint far more pervasive than many of us care to acknowledge. We must have input at the planning stage that is constructive and professional; where there are differences they should be based on facts and logic rather than myth and personal aggrandizement.

We have a planning process for timber management and district planning teams. They have worked and I believe we 
should set about making them work even better. There is a topic that so far has not been addressed squarely, in fact it's hardly been mentioned, but I believe it is related to concerns expressed by Mike Opper about industry's responsibilities. It is the question of responsibility and accountability. I want to emphasize that there can be no abrogation of the District Manager's role as the local representative of the landowner. A planning team can have lots of good input but ultimately the plan and its implementation is the responsibility of the forester who prepared it. Is he or she to be held accountable for objectives not reached by activities undertaken to benefit other values? This is a question we have yet to answer satisfactorily.

\section{Investment}

There are several forms of investment in forestry and wildlife management. People, time, equipment, the resource itself in a sense, and they all boil down to a common denominator - money.

With Forest Management Agreements, Ontario embarked upon a course - as owner of the forest resource - in partnership with the forest industry to manage and jointly invest to provide timber to the forest industry. The integration of harvesting and regeneration recognized that those planning and actively engaged in the manipulation of the forest were best suited to achieve timber production objectives. Several speakers have raised the question whether or not, by extension this does not equally apply to forest management for wildlife. The suggestion that the forest companies undertaking management employ wildlife biologists or rent their expertise has been made and I believe this could be a very fruitful development.

The problem is that we haven't yet clearly identified what investments, if any, are appropriate to meet specified wildlife objectives, who will make them and under what arrangements. There is no immediate answer but I would suggest that the growing interest in what have been called "stewardship contracts" or "end result contracts (ERCs)" now being touted for forest regeneration bear looking at for certain wildlife management activities. They may well fit into the FMA process.

\section{Ecosystem Management}

So much for a brief overview on structure, development and investment. There were certain broader issues that have been touched upon. We were cautioned about the use of existing data to draw conclusions about relationships between wildlife populations and forestry activities, for example, furbearer statistics. It is often such conclusions that form the basis for adversarial positions.

We were also advised to recognize that while Alces alces may be the boreal Godfather for many biologists, there are a host of other organisms both plant and animal about which we should be concerned. This line of thought tends to lead down the path to what some would say is the need to manage the forest as an 'ecosystem'.

Let me demonstrate my bias at once. I believe that while that path may be trod with the best of intentions, it is a "primrose path to hell". The term ecosystem connotes a concept. We don't manage concepts in our forests! We manage tangible resources - trees and wildlife. I am not arguing about the concept itself which should, in fact, lie behind our decisions and activities.

We are bringing a natural wild forest under some degree of management. In so doing we are only active in a very small fraction of that forest at any one time and it will be many decades before a significant portion can be said to be fully managed. I believe we have to show, as strenuously and honestly as we can, that the activities we are engaged in for management of timber and wildlife do not result in any significant deleterious effects to "the ecosystem". The corollary of this is that if there are specific instances of rare organisms that realistically may be threatened, then we should be willing to ensure that we do all that is possible to remove that threat.

Finally, I, like Guy Winterton, am optimistic. I am no 'rear view mirror' person but I believe a look back shows that we are already moving up a learning curve. I am sure that by paying more attention to the design elements of our forest management - the careful delineation of long and short rotation 'new' forests - and by setting aside certain old growth stands that we can provide an exciting challenge to foresters and biologists alike, and achieve better management that will be cost effective, efficient and meet the needs of Ontarians of today and tomorrow. 